\title{
Design Optimization and In Vitro-In Vivo Evaluation of Orally Dissolving Strips of Clobazam
}

\author{
Rajni Bala, ${ }^{1}$ Sushil Khanna, ${ }^{2}$ and Pravin Pawar ${ }^{1}$ \\ ${ }^{1}$ Chitkara College of Pharmacy, Chandigarh-Patiala National Highway, Rajpura, Patiala, Punjab 140 401, India \\ ${ }^{2}$ Crest Healthcare Pvt. Ltd., Baddi, Himachal Pradesh 173205, India \\ Correspondence should be addressed to Pravin Pawar; pravin.pawar@chitkara.edu.in
}

Received 25 May 2014; Revised 3 August 2014; Accepted 17 August 2014; Published 28 September 2014

Academic Editor: Jaleh Varshosaz

Copyright (c) 2014 Rajni Bala et al. This is an open access article distributed under the Creative Commons Attribution License, which permits unrestricted use, distribution, and reproduction in any medium, provided the original work is properly cited.

\begin{abstract}
Clobazam orally dissolving strips were prepared by solvent casting method. A full $3^{2}$ factorial design was applied for optimization using different concentration of film forming polymer and disintegrating agent as independent variable and disintegration time, $\%$ cumulative drug release, and tensile strength as dependent variable. In addition the prepared films were also evaluated for surface $\mathrm{pH}$, folding endurance, and content uniformity. The optimized film formulation showing the maximum in vitro drug release, satisfactory in vitro disintegration time, and tensile strength was selected for bioavailability study and compared with a reference marketed product (frisium5 tablets) in rabbits. Formulation (F6) was selected by the Design-expert software which exhibited DT $(24 \mathrm{sec})$, TS $\left(2.85 \mathrm{~N} / \mathrm{cm}^{2}\right)$, and in vitro drug release $(96.6 \%)$. Statistical evaluation revealed no significant difference between the bioavailability parameters of the test film (F6) and the reference product. The mean ratio values (test/reference) of $C_{\max }(95.87 \%$ ), $t_{\max }(71.42 \%), \mathrm{AUC}_{0-t}(98.125 \%)$, and $\mathrm{AUC}_{0-\infty}(99.213 \%)$ indicated that the two formulae exhibited comparable plasma level-time profiles.
\end{abstract}

\section{Introduction}

Oral route is one of the most preferred routes of drug administration due to its safety, ease of administration, and acceptability by patients. About $60 \%$ of conventional dosage forms are available as the oral solid dosage forms [1]. The low bioavailability, longer onset of action, and dysphasia patients turned the manufacturer towards the parenterals and liquid dosage forms. But the liquid dosage forms (syrup, suspension, emulsion, etc.) have the problem of accurate dosing and parenterals are painful drug delivery systems, so they result in patient incompliance. The most popular oral dosage forms are tablets and capsules; one major drawback of these dosage forms is the difficulty to swallow [2]. Drinking water plays an important role in the swallowing of oral dosage forms. People experience inconvenience in swallowing tablet dosage forms when water is not available particularly in the case of traveling (motion sickness) and sudden episodes of coughing during the common cold, allergic condition, and bronchitis. Under such circumstances, tablets that can rapidly dissolve or disintegrate in the oral cavity known as fast dissolving tablets have attracted a great deal of attention. Fast dissolving tablets are also known as mouth-dissolving tablets, orodispersible tablets, rapidmelts, and porous tablets. Fast dissolving tablets dissolve or disintegrate within 60 seconds when placed in the mouth without drinking water or chewing. The active ingredients are absorbed through mucous membranes in the mouth and GIT and enter the blood stream [3]. But due to certain disadvantages like their physical solid form, psychological fear of swallowing, chewing, or chocking, friability of wafer like porous and low pressure moulded tablet, and expensive packaging cost of these dosage forms to protect them, a new technology was developed as orally dissolving strip. Orally dissolving strips are the most advanced form of oral solid dosage form due to more flexibility and comfort [4]. It improves the efficacy of APIs by dissolving within a minute in oral cavity after the contact with saliva without chewing and need of water for administration. It gives quick absorption and instant bioavailability of drugs due to high blood flow and 
permeability of oral mucosa which is 4-1000 times greater than that of skin. Orally dissolving strips are useful in patients such as pediatrics, geriatrics, bedridden, and emetic patients and conditions such as sudden episodes of allergic attacks or coughing. They can be used for local and systemic delivery. There is an increasing interest in the development of orally dissolving strips as an alternative to fast dissolving tablets [5], due to their faster dissolution rate, higher flexibility, and better patient compliance. Presently, research work on the use of orally dissolving strips as promising carriers for the delivery of multiple active pharmaceutical ingredients has emerged [6-11]. Marketed orally dissolving strips products have also become available including Listerine, Chloraseptic, Triaminic, and multivitamins [12]. The backbone of an orally dissolving strip is generally formed of a plasticizer and film forming polymer or a mixture of polymers that provide the necessary elasticity and shape to the film. Examples of polymers that have been used in the formulation of orally dissolving strips include hydrocolloids or povidone K90 [13], maltodextrin (MDX), hydroxypropyl ethylcellulose (HPMC-E15, 5), pectin, sodium alginate [14], or blends of polymers [15]. Orally dissolving strips can be prepared using a solvent-casting, rolling, hot melt extrusion, or solid dispersion methods. Epilepsy is a condition characterized by the repeated attacks of epileptic seizures. Epileptic seizures can occur in nonepileptic patients subjected to a variety of stresses and stimuli. Epilepsy is a neurological disorder which requires quick management of seizures in order to avoid the risk of permanent brain damage [16]. Pharmacotherapy with antiepileptic drugs remains the major treatment modality for epilepsy. Management of epilepsy differs from the treatment of other diseased conditions in that a single epileptic attack has a major negative effect on quality of life. Clobazam is a newer 1,5-benzodiazepine derivative which is a well tolerated, safe, and very effective antiepileptic drug having a broad spectrum of antiepileptic activity and minimal side effects and being relatively inexpensive. Its wider use is recommended in children with intractable epilepsy [17]. Thus, to control the epileptic seizures in the shortest possible time, an attempt has been made to develop, evaluate, and optimize orally dissolving strips of clobazam with improved bioavailability and palatability. Clobazam is an ideal drug candidate for an orally dissolving strip formulation because of its indication in children and its low-dose requirement. The formulation of clobazam as an orally dissolving strip, required to be placed on the patient's tongue without swallowing for dose administration, would significantly facilitate dose administration, with subsequent improvement in patient compliance. Thus, the aim of this work was to design, characterize, and optimize orally dissolving strip of clobazam using two polymers: SSG (disintegrant) and PVA (film former). A $3^{2}$ factorial design was used to evaluate the influence of film forming polymer PVA and disintegrating agent SSG on the film's mechanical properties, disintegration time, and dissolution rate. This study also assessed the in vivo performance and IVIVC of the optimum formulation by administration to healthy rabbits.

\section{Material and Method}

2.1. Material. Clobazam was received as a gift sample from Consern Pharma Pvt. Ltd., Ludhiana, India. Sodium starch glycolate, PEG-400, and directly compressible mannitol were received from Loba chemie Pvt. Ltd., Mumbai, India. Polyvinyl alcohol was procured from Central Drug House Pvt. Ltd., New Delhi, India. All other chemicals used were of analytical reagent grade.

2.2. Fourier Transform Infrared (FTIR) Analysis. The pure drug clobazam and physical mixture of clobazam and polymers were mixed with IR grade KBR pellets in the ratio of $100: 1$ and corresponding pellets were prepared in a hydraulic press. The pellets were scanned over a wave number range of $4000-500 \mathrm{~cm}^{-1}$ in using Perkin Emler spectrum 400USA, FTIR instrument.

2.3. Differential Scanning Calorimetric (DSC) Analysis. Differential scanning calorimetry (DSC) analysis was undertaken to visualize the changes, if any, observed during the preparation of the orally dissolving strip using Mettler Toledo model DSC 821e instrument. DSC of clobazam (pure drug), physical blend of PVA, clobazam and SSG (polymer), and optimized film formulation F6 were carried out over a temperature range of 30 to $300^{\circ} \mathrm{C}$ at a scanning rate of $5^{\circ} \mathrm{C} / \mathrm{min}$.

2.4. Solubility Studies of Pure Clobazam in Phosphate Buffer pH 6.8 and Different Solvents. Solubility studies were carried out by taking [18] an excess amount of drug in $10 \mathrm{~mL}$ of different solvents and $\mathrm{pH} 6.8$ buffers in conical flask, closed with aluminum foil and constantly agitated at room temperature for $24 \mathrm{hrs}$, using orbital shaking incubator (Remi Instruments, C-24 BL, and Mumbai, India). Further, the solutions were filtered and the amount of drug solubilised was estimated at a wave length of $232 \mathrm{~nm}$ by using Systronics PC based double beam spectrophotometer 2202, Mumbai, India.

2.5. Preparation of Orally Dissolving Strips. The orally dissolving strips of clobazam using film forming polyvinyl acetate (PVA) and PEG 400 as plasticizer were prepared by solventcasting method [19]. An aqueous solution of the polymer was prepared in warm distilled water and was kept aside for 4 hours for swelling of polymer. Clobazam was added to the aqueous polymeric solution after levigation with required volume of PEG 400. This was followed by the addition of mannitol as a sweetener as well as a solubilizer and sodium starch glycolate as a superdisintegrant. The solution was casted on a plastic Petri dish and dried at room temperature for $24 \mathrm{hr}$. The strip was carefully removed from the Petri dish, checked for any imperfections, and cut into the required size $\left(2 \times 2 \mathrm{~cm}^{2}\right)$ to deliver the equivalent dose of $5 \mathrm{mg}$ per strip. The film samples were stored in desiccators for further analysis. Preliminary trials were undertaken for designing the orally dissolving strips where the effect of various concentrations of the film forming agent and superdisintegrants on the characteristics of the strips was noted. In addition, 
TABLE 1: Independent variables and their levels.

\begin{tabular}{lccc}
\hline Variables & Low level $(-1)$ & Medium level $(0)$ & High level $(+1)$ \\
\hline$X_{1}=$ amount of SSG $(\%)$ & 2 & 4 & 6 \\
$X_{2}=$ amount of PVA $(\mathrm{mg})$ & 50 & 100 & 200 \\
\hline
\end{tabular}

TABLE 2: Factorial design with disintegration time, tensile strength, and $\%$ drug release obtained.

\begin{tabular}{lccccc}
\hline Run & Factor $X_{1}$ & Factor $X_{2}$ & DT $(\mathrm{sec})$ & TS $\left(\mathrm{N} / \mathrm{cm}^{2}\right)$ & $\%$ drug release \\
\hline 1 & -1 & -1 & $32 \pm 2.0$ & $1.43 \pm 0.03$ & $1.68 \pm 0.01$ \\
2 & 0 & -1 & $27.3 \pm 3.1$ & $1.057 \pm 0.02$ & 85 \\
3 & +1 & -1 & $26.3 \pm 1.0$ & $2.18 \pm 0.03$ & 79 \\
4 & -1 & 0 & $34 \pm 2.0$ & $2.38 \pm 0.03$ & 83.1 \\
5 & 0 & 0 & $28 \pm 1.0$ & $2.85 \pm 0.03$ & 96.6 \\
6 & +1 & +1 & $24 \pm 0.5$ & $3.61 \pm 0.05$ & 68.9 \\
7 & -1 & +1 & $36 \pm 2.1$ & $3.73 \pm 0.03$ & 70 \\
8 & 0 & +1 & $29 \pm 1.0$ & $3.79 \pm 0.02$ & 82.1 \\
9
\end{tabular}

DT $=$ disintegration time.

$\mathrm{TS}=$ tensile strength.

TABLE 3: Composition of different orally dissolving strips containing clobazam.

\begin{tabular}{|c|c|c|c|c|c|c|c|c|c|}
\hline \multirow{2}{*}{ Ingredients } & \multicolumn{9}{|c|}{ Formulation batches } \\
\hline & $\mathrm{F} 1$ & F2 & F3 & $\mathrm{F} 4$ & F5 & F6 & F7 & F8 & F9 \\
\hline Clobazam (mg) & 5 & 5 & 5 & 5 & 5 & 5 & 5 & 5 & 5 \\
\hline PVA (mg) & 50 & 50 & 50 & 100 & 100 & 100 & 200 & 200 & 200 \\
\hline PEG 400 (mg) & 0.3 & 0.3 & 0.3 & 0.3 & 0.3 & 0.3 & 0.3 & 0.3 & 0.3 \\
\hline SSG (mg) & 2 & 4 & 6 & 2 & 4 & 6 & 2 & 4 & 6 \\
\hline D-Mannitol (mg) & 25 & 25 & 25 & 25 & 25 & 25 & 25 & 25 & 25 \\
\hline Water (mL) & 10 & 10 & 10 & 10 & 10 & 10 & 10 & 10 & 10 \\
\hline
\end{tabular}

The concentration of the drug was $5 \mathrm{mg} / 4 \mathrm{~cm}^{2}$ of the film.

the prepared strips were also checked for surface perfection, smoothness, and ease of removal from Petri dish without rupturing, folding, or cracking.

\subsection{Preparation of Orally Dissolving Strips of Clobazam Using} $3^{2}$ Factorial Designs. A $3^{2}$ full factorial design was employed to study the effect of independent variables $X_{1}$ (PVA) and $X_{2}$ (SSG) over the dependent variables like tensile strength $\left(\mathrm{N} / \mathrm{cm}^{2}\right)$, disintegration time $(\mathrm{sec})$, and in vitro drug release (\%) as shown in design layout Tables 1 and 2. In this design, two factors were evaluated each at three levels $(-1,0,+1)$ and all possible nine experimental batches were formulated. Composition of all nine possible combinations of orally dissolving strip of clobazam using $3^{2}$ full factorial designs is shown in Table 3. The data was subjected to contour and 3D response surface plot using Design-expert software version 8.0.7.1. A multiple linear regression equation incorporating interactive and polynomial terms was used to calculate the response as follows:

$$
Y=b_{0}+b_{1} X_{1}+b_{2} X_{2}+b_{12} X_{1} X_{2}+b_{11} X_{1}^{2}+b_{22} X_{2}^{2},
$$

where $Y$ is the dependent, that is, response variable, namely, disintegration time, tensile strength, and in vitro drug release; $b_{0}$ is the arithmetic mean response of the nine runs; and $b_{1}$ and $b_{2}$ are the estimated coefficients for the factors $X_{1}$ and $X_{2}$, respectively. The main effects $\left(X_{1}\right.$ and $\left.X_{2}\right)$ represent the average result of changing one factor at a time from its low to high value. The interaction term $\left(X_{1} X_{2}\right)$ shows how the response changes when two factors are simultaneously changed. The polynomial terms $\left(X_{1}^{2}\right.$ and $\left.X_{2}^{2}\right)$ are used to check nonlinearity. The polynomial equations can be used to draw conclusions after considering the magnitude of the coefficient and the mathematical sign it carries (i.e., positive or negative). The high values of the correlation coefficients for the dependent variables indicate a good fit.

\subsection{Physicochemical Characterization of Clobazam Orally Dissolving Strips}

2.7.1. Film Weight and Thickness. The thickness of each strip was measured at five different locations (centre and four corners) using calibrated digital Vernier caliper (Mituotoyo, Japan). Data are represented as a mean \pm SD of three replicate determinations. 
2.7.2. Folding Endurance. The folding endurance was measured manually for the prepared strips. A strip of $\left(2 \times 2 \mathrm{~cm}^{2}\right)$ was cut and repeatedly folded at the same place till it broke. The number of times the strip could be folded at the same place without breaking was taken as a measure of folding endurance.

2.7.3. Drug Content Determination. The oral strip of size $4 \mathrm{~cm}^{2}$ was dissolved in $10 \mathrm{~mL}$ of phosphate buffer $\mathrm{pH} 6.8$ and solution was filtered and drug content was estimated at $232 \mathrm{~nm}$ using double beam UV/Visible spectrophotometer (Systronics 2202, Mumbai, India). The experiments were carried out in triplicate for the strips of all formulations and average values were recorded [20].

2.7.4. Surface $p H$. The surface $\mathrm{pH}$ of orally dissolving strips was determined in order to investigate the possibility of any side effects in vivo. As an acidic or alkaline $\mathrm{pH}$ may cause irritation to the oral mucosa, it is determined to keep the surface $\mathrm{pH}$ as close to neutral as possible. Strip was wetted with the help of water. The $\mathrm{pH}$ was measured by bringing the electrode in contact with the surface of the oral strip. This study was performed on three strips of each formulation and mean \pm SD calculated [21].

2.7.5. In Vitro Disintegration Time of Orally Dissolving Strip of Clobazam. In vitro disintegration time was measured by placing the film $\left(2 \times 2 \mathrm{~cm}^{2}\right)$ on stainless steel wire mesh placed in a Petri dish containing $10 \mathrm{~mL}$ of phosphate buffer $\mathrm{pH} 6.8$. Time required for the oral strip to break was noted as in vitro disintegration time. The test was performed on three strips of each formulation batch and mean \pm SD was calculated [22]

2.7.6. In Vitro Dissolution Studies of Clobazam Orally Dissolving Strip. In vitro dissolution test was performed according to the USP type II paddle apparatus (Labindia DS 8000, Mumbai, India). Test was performed by fixing the oral strip $\left(2 \times 2 \mathrm{~cm}^{2}\right)$ to rectangular glass plates so as to prevent it from floating and it was placed at the bottom of dissolution vessel containing $900 \mathrm{~mL}$ of phosphate buffer $\mathrm{pH} 6.8$ at $37^{\circ} \mathrm{C}$ with a rotation speed of $50 \mathrm{rpm}$. A $5 \mathrm{~mL}$ of sample was taken at time intervals from 1 to $30 \mathrm{~min}$, and the same volume was replenished with fresh buffer solution maintained at $37^{\circ} \mathrm{C}$. The samples were filtered and analyzed at $232 \mathrm{~nm}$ using double beam UV/Visible spectrophotometer (Systronics 2202, Mumbai, India); the content of drug was calculated using equation generated from standard calibration curve of clobazam. The release mechanism of clobazam from oral strip was also determined by fitting the release data to different kinetic models, zero order [23], first order [24], and Higuchi [25].

2.7.7. Surface Morphology. The surface morphology of the optimized orally dissolving strip formulation was observed with scanning electron microscope (Hitachi S-3400N type II model, Japan). Pictures were taken at an excitation voltage of $1.0 \mathrm{KV}$ and a magnification of $1000 \mathrm{x}$.

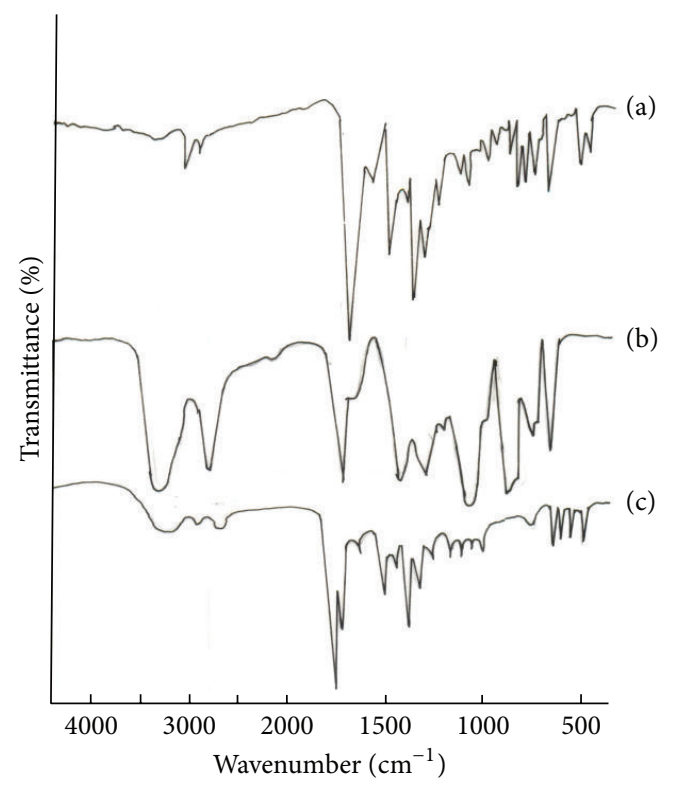

FIGURE 1: FTIR of (a) clobazam, (b) PVA, and (c) physical mixture of clobazam and PVA.

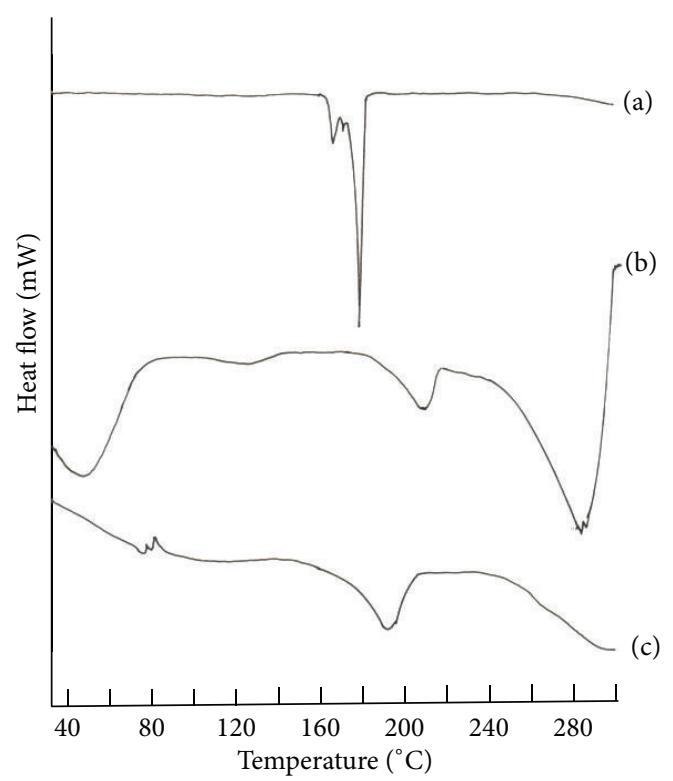

FIGURE 2: DSC thermogram of (a) clobazam, (b) F6, and (c) physical blend of clobazam, PVA, and SSG.

2.7.8. Determination of Moisture Uptake. Films were cut into $2 \times 2 \mathrm{~cm}$ square strips $\left(4 \mathrm{~cm}^{2}\right)$. The moisture uptake by the strip $(n=3)$ was determined by exposing them to an environment of $75 \%$ relative humidity $(\mathrm{RH})$ at room temperature $\left(25 \pm 2^{\circ} \mathrm{C}\right)$ for 1 week $[26,27]$. The uptake of moisture by the strips was measured and calculated as percent increase in weight.

2.7.9. Tensile Strength of Orally Dissolving Strips of Clobazam. Tensile strength testing was determined at Central Institute of Post Harvesting Engineering and Technology (CIPHET), 
TABLE 4: Characterization of different orally dissolving strips of clobazam.

\begin{tabular}{lcccr}
\hline Formulae & \% drug content & Thickness $(\mathrm{mm})$ & $\% E$ & Folding endurance \\
\hline F1 & $96 \pm 3.05$ & $0.14 \pm 0.05$ & $10 \pm 1.1$ & $200 \pm 3.54$ \\
F2 & $98.53 \pm 0.74$ & $0.21 \pm 0.1$ & $20 \pm 1.2$ & $210 \pm 2.44$ \\
F3 & $98.49 \pm 2.54$ & $0.22 \pm 0.06$ & $25 \pm 0.5$ & $280 \pm 2.53$ \\
F4 & $99.11 \pm 0.64$ & $0.26 \pm 0.1$ & $25 \pm 1.44$ & $283 \pm 0.44$ \\
F5 & $97.73 \pm 0.50$ & $0.27 \pm 0.2$ & $50 \pm 1.43$ & $280 \pm 4.12$ \\
F6 & $99.96 \pm 4.17$ & $0.29 \pm 0.05$ & $150 \pm 1.01$ & $284 \pm 1.22$ \\
F7 & $98.54 \pm 1.66$ & $0.26 \pm 0.05$ & $50 \pm 1.23$ & $150 \pm 0.44$ \\
F8 & $97.93 \pm 4.22$ & $0.27 \pm 0.3$ & $75 \pm 1.44$ & $200 \pm 2.34$ \\
F9 & $98.41 \pm 3.23$ & $0.27 \pm 0.1$ & $80 \pm 1.11$ & 7.0 \\
\hline
\end{tabular}

$\% E=\%$ elongation.

Values are expressed as mean $\pm \mathrm{SD} ; n=3$.

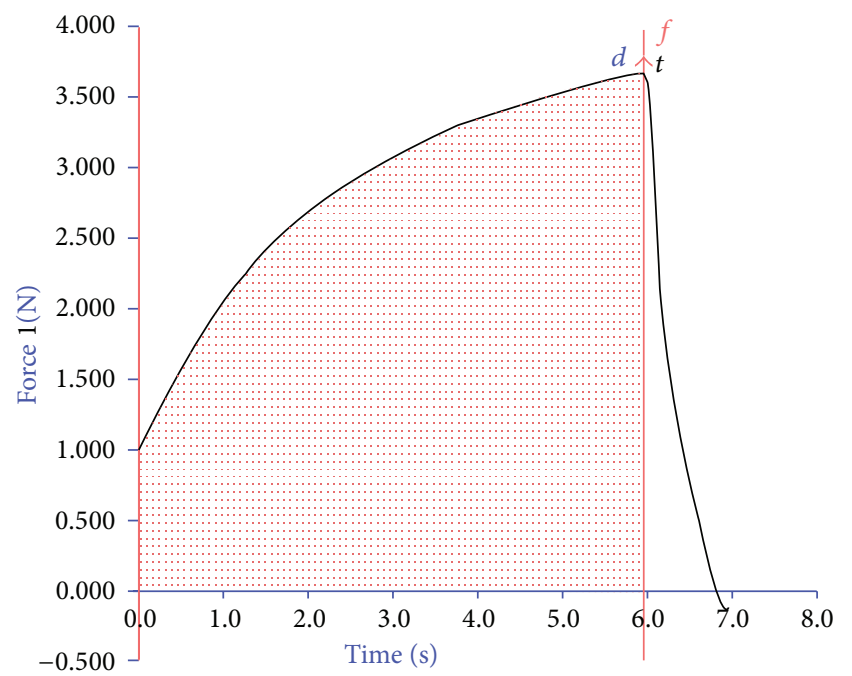

FIGURE 3: Strain-stress curves of the clobazam optimized ODF F6.

Ludhiana, India, using a texture analyzer TAHDi (stable microsystem), equipped with a $5 \mathrm{~kg}$ load cell. The strip was cut into $100 \times 12.5 \mathrm{~mm}$ strips and equilibrated at $25^{\circ} \mathrm{C}$ for 1 week. Each test strip was longitudinally placed in the tensile grips on the texture analyzer. Initial grip separation was $60 \mathrm{~mm}$ and crosshead speed was $50 \mathrm{~mm} \mathrm{~min}^{-1}$. The test was considered concluded at the point where the oral strip breaks. Tensile strength, elongation at break, was computed to evaluate the tensile properties of the strips. Tensile strength (TS) was calculated by dividing the maximum load by the original cross-sectional area of the strip and it was expressed as $\left(\mathrm{N} / \mathrm{cm}^{2}\right)$. Percent elongation at break $(E \%)$ was calculated by dividing the length at the time of break of the strip by the initial length of the strip and multiplying by 100 using the following equation:

$$
E \%=\frac{L-L_{0}}{L_{0}} \times 100
$$

where $L_{0}$ is the initial length of the strip and $L$ is the length at the time of break. An average of three measurements was taken for each formulation [28].

\begin{abstract}
2.8. HPLC Method Validation Used to Quantify Clobazam in Rabbit Plasma. The calibration curve was performed with standards of the final concentrations of 5, 10, 25, 50, and $100 \mathrm{ng} / \mathrm{mL}$ in rabbit plasma [29]. The intraday, interday precisions and accuracy of the method were determined with three replicates spiked plasma samples at different concentrations of clobazam. The intraday and interday variation was calculated in terms of percent relative to standard deviation.
\end{abstract}

2.9. Pharmacokinetic Study of Selected Clobazam Orally Dissolving Strip Formulation. The study was conducted in accordance with the principles of laboratory animal care. Six rabbits of either sex (weighed $2.5 \pm 0.2 \mathrm{~kg}$ ) were selected for the study. All the rabbits were healthy during the period of study. All the rabbits were fasted overnight before the administration of the selected fast dissolving film and marketed formulation but had free access to water. The rabbits were randomly divided into two groups with each group containing three rabbits $(n=3)$. The rabbits were positioned on a table with lower jaw supported in a horizontal position and orally dissolving strip was carefully placed on the rabbit tongue in one group as shown in Figure 12. The marketed tablet was administered orally to another group. Blood samples for pharmacokinetic analysis were collected from marginal ear veins of rabbits immediately before drug administration and at $5,10,15,30,60,120,180 \mathrm{~min}, 6 \mathrm{hrs}, 12$, and $24 \mathrm{hrs}$ interval. The plasma samples were prepared by mixing $0.1 \mathrm{~mL}$ of plasma with $0.05 \mathrm{~mL}$ ibuprofen as internal standard (from the stock $6000 \mathrm{ng} / \mathrm{mL}$ ) in a clean Eppendorf polypropylene tube and then extracting with $1.5 \mathrm{~mL}$ of acetonitrile after vertical agitation $(1 \mathrm{~min})$ and centrifugation at $1000 \mathrm{rpm}$, for $5 \mathrm{~min}$. The upper organic layer was injected onto the HPLC system for analysis. The HPLC analysis was performed using Agilent 1200 series system by using a mobile phase composed of water $\mathrm{pH} 3.5$, adjusted with orthophosphoric acid and acetonitrile $(55: 45 \mathrm{v} / \mathrm{v})$, and binary eluted at a flow rate of $1.5 \mathrm{~mL} \mathrm{~min}^{-1}$ [30]. Protocols for all the animal studies were approved by institutional ethical committee [IAEC/CCP/12/PR-007].

2.10. Calculation of Pharmacokinetic Parameters. Plasma concentration time profile curve of clobazam was plotted. Maximum plasma concentration $C_{\max }$ and the time $t_{\max }$ were 


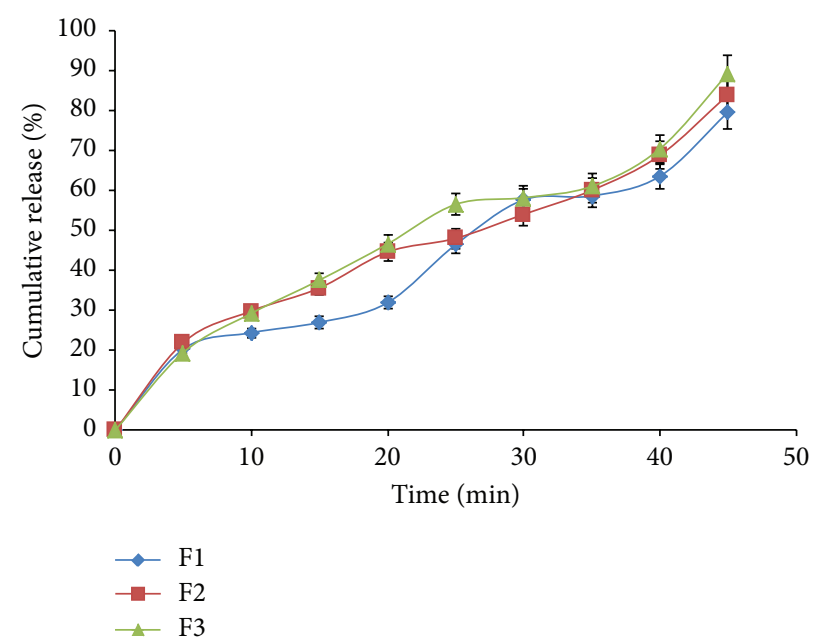

(a)

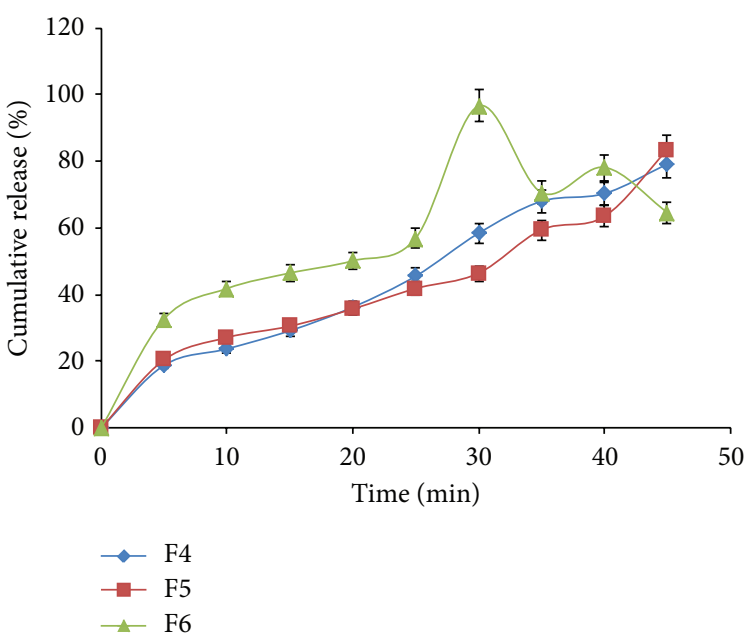

(b)

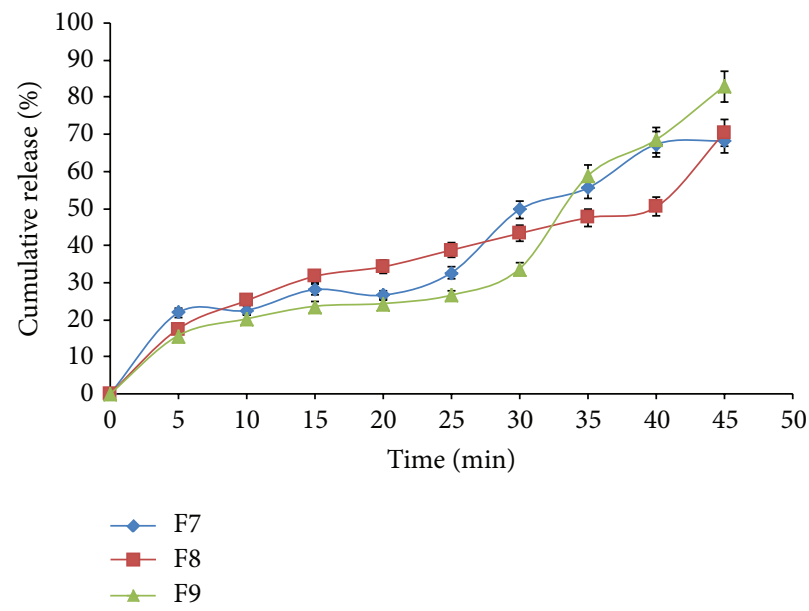

(c)

FIGURE 4: Clobazam release profiles from ODF formulations containing different levels of PVA as film former and SSG as superdisintegrant, (a) F1, F2, and F3, (b) F5, F6, and F7, and (c) F7, F8, and F9. Mean \pm SD, $n=3$.

obtained directly from the individual plasma concentration versus time curves. The terminal half-life, $t_{1 / 2}$, was obtained from log linear regression analysis of the plasma concentration time curves in the terminal phase. The area under plasma concentration time curve $\left(\mathrm{AUC}_{0-t}\right.$, and $\left.\mathrm{AUC}_{0-\infty}\right)$ was determined by linear trapezoidal method. For $90 \%$ confidence interval, the AUC and $C_{\max }$ values were transformed into their respective logarithms and analysis of variance was calculated using software Kinetica 5.0. Trial version Adept Scientific limited.

2.11. IVIV Correlation. In vitro and in vivo correlations were carried out to compare the release of drug. Here, the in vivo percentage of the drug absorbed was plotted against the in vitro percentage of the drug released to determine the correlation coefficient. The fraction of the drug absorbed was determined using the Wagner Nelson method, using the following equation [31]:

$$
F_{a}=\left[\frac{\left(C_{t}+k_{e} \mathrm{AUC}_{0-t}\right)}{k_{e} \mathrm{AUC}_{0-\infty}}\right] \times 100,
$$

where $F_{a}$ is the fraction of drug absorbed, $C_{t}$ is the plasma drug concentration at time $t, k_{e}$ is the overall elimination rate constant, and $\mathrm{AUC}_{0-t}$ and $\mathrm{AUC}_{0-\infty}$ are areas under the curve between time zero and time $t$ and between time zero and infinity, respectively.

2.12. Stability Studies. The optimized orally dissolving formulation of clobazam was subjected to stability studies by packing the individual strip in aluminum foil and loading the formulation on Remi stability chamber SC-10 Plus (Remi elektrotechnik Ltd., Vasai, India) as per ICH guidelines 
TABLE 5: Release kinetic study of orally dissolving strips of clobazam using different kinetic models.

\begin{tabular}{|c|c|c|c|c|c|}
\hline \multirow[b]{2}{*}{ Formulation code } & \multicolumn{5}{|c|}{ Kinetic models } \\
\hline & $\begin{array}{c}\text { Zero order } \\
r^{2}\end{array}$ & $\begin{array}{c}\text { First order } \\
r^{2}\end{array}$ & $\begin{array}{c}\text { Higuchi } \\
r^{2}\end{array}$ & $\begin{array}{c}\text { Korsmeyer } \\
r^{2}\end{array}$ & Best fit kinetic \\
\hline $\mathrm{F} 1$ & 0.947 & 0.826 & 0.971 & 0.967 & Higuchi \\
\hline $\mathrm{F} 2$ & 0.924 & 0.961 & 0.996 & 0.984 & Higuchi \\
\hline F3 & 0.978 & 0.984 & 0.997 & 0.986 & Higuchi \\
\hline $\mathrm{F} 4$ & 0.965 & 0.950 & 0.989 & 0.952 & Higuchi \\
\hline F5 & 0.985 & 0.952 & 0.994 & 0.992 & Higuchi \\
\hline F6 & 0.952 & 0.861 & 0.998 & 0.993 & Higuchi \\
\hline F7 & 0.702 & 0.703 & 0.987 & 0.929 & Higuchi \\
\hline F8 & 0.959 & 0.933 & 0.996 & 0.980 & Higuchi \\
\hline F9 & 0.848 & 0.881 & 0.988 & 0.980 & Higuchi \\
\hline
\end{tabular}

TABLE 6: Summary of results of regression analysis.

\begin{tabular}{lcccccc}
\hline Coefficient & $b_{0}$ & $b_{1}$ & $b_{2}$ & $b_{12}$ & $b_{11}$ & $b_{22}$ \\
\hline Disintegration time $(\mathrm{sec})$ & 28.32222 & 1.56667 & -4.3333 & -0.07500 & -0.333 & 1.6667 \\
Tensile strength $\left(\mathrm{N} / \mathrm{cm}^{2}\right)$ & 2.3911 & -0.56500 & 0.31167 & -0.01500 & -0.1916 & 0.12833 \\
\% drug release & 81.70 & -5.1683 & 5.1683 & 0.100250 & -4.5016 & 0.9242 \\
\hline
\end{tabular}

$b_{0}, b_{1}, b_{2}, b_{12}, b_{11}$, and $b_{22}$ represent regression coefficient of the independent variables $\left(X_{1}, X_{2}\right)$.

TABLE 7: Comparison of observed and predicted values with \% prediction error.

\begin{tabular}{lccc}
\hline Variables & Predicted value & Observed value & \% prediction error \\
\hline Disintegration time $(\mathrm{sec})$ & 23.8 & 24 & $0.833 \%$ \\
$\%$ drug release & 97.8 & 96.6 & $1.24 \%$ \\
Tensile strength $\left(\mathrm{N} / \mathrm{cm}^{2}\right)$ & 2.90 & 2.85 & $-1.75 \%$ \\
\hline
\end{tabular}

for 180 days at $40^{\circ} \mathrm{C} \pm 2^{\circ} \mathrm{C} / 75 \% \mathrm{RH} \pm 5 \%$. Samples were withdrawn at regular intervals and evaluated for in vitro drug release, disintegration time, and tensile strength.

\section{Results and Discussion}

3.1. Fourier Transform Infrared (FTIR) Analysis. FTIR spectra of pure drug and physical mixture of PVA and clobazam as shown in Figures 1(a), 1(b), and 1(c) indicate that there was no interaction between drug and film forming polymer used. Pure clobazam displays a peak characteristic of $\mathrm{C}=\mathrm{O}$ stretching vibration at $1694.7 \mathrm{~cm}^{-1}$, aromatic $\mathrm{CH}$ stretching at $3075.4 \mathrm{~cm}^{-1}$, C-C stretching at $1493.5 \mathrm{~cm}^{-1}, \mathrm{C}-\mathrm{N}$ stretching at $1100-1200 \mathrm{~cm}^{-1}, \mathrm{CH}$ bending at $600-800 \mathrm{~cm}^{-1}$, and $\mathrm{CH}_{3}$ bending at $1371 \mathrm{~cm}^{-1}$; the spectra of drug with PVA showed all characteristics peaks of drug indicating that the drug is compatible with PVA.

3.2. Differential Scanning Thermograms. DSC thermograms of clobazam (pure drug), PVA (polymer), clobazam and SSG, and clobazam loaded orally dissolving strip as shown in Figures 2(a), 2(b), and 2(c) illustrated a sharp endothermic peak corresponding to the melting of crystalline clobazam at $180^{\circ} \mathrm{C}$. The melting endothermic peak of clobazam was not observed in the drug loaded PVA orally dissolving strip. This indicates that clobazam was uniformly dispersed and present in an amorphous state in the polymeric matrix.

\subsection{Physicochemical Characterization of Clobazam Orally} Dissolving Strip. Physicochemical characterization of clobazam films as given in Table 4 indicated that all the strips prepared with different polymer concentrations were flexible, smooth, transparent, nonsticky, and homogeneous. The thickness of the oral strip varies from 0.140 to $0.29 \mathrm{~mm}$. It was observed that there was no significant difference in the thickness among the strips, which indicated that the orally dissolving strips were uniform. The weight of oral strips varies from 43.0 to $63.0 \mathrm{mg}$. The folding endurance of the oral strips varies from 150 to 284 . F6 exhibited good folding endurance, indicating good flexibility. The folding endurance increases with the increasing content of PVA. However, the folding endurance of the oral strip F7-F9 was found to decrease with increasing content of PVA. Thus, it appears that the increasing amount of PVA decreases the flexibility of the strip. Since the surface $\mathrm{pH}$ of orally dissolving strips was found to be around neutral $\mathrm{pH}$, there will not be any kind of irritation to the mucosal lining of the oral cavity. All formulations were found to contain uniform quantities of drug ranging between $97.93 \%$ and $99.96 \%$, as indicated by content uniformity studies. 

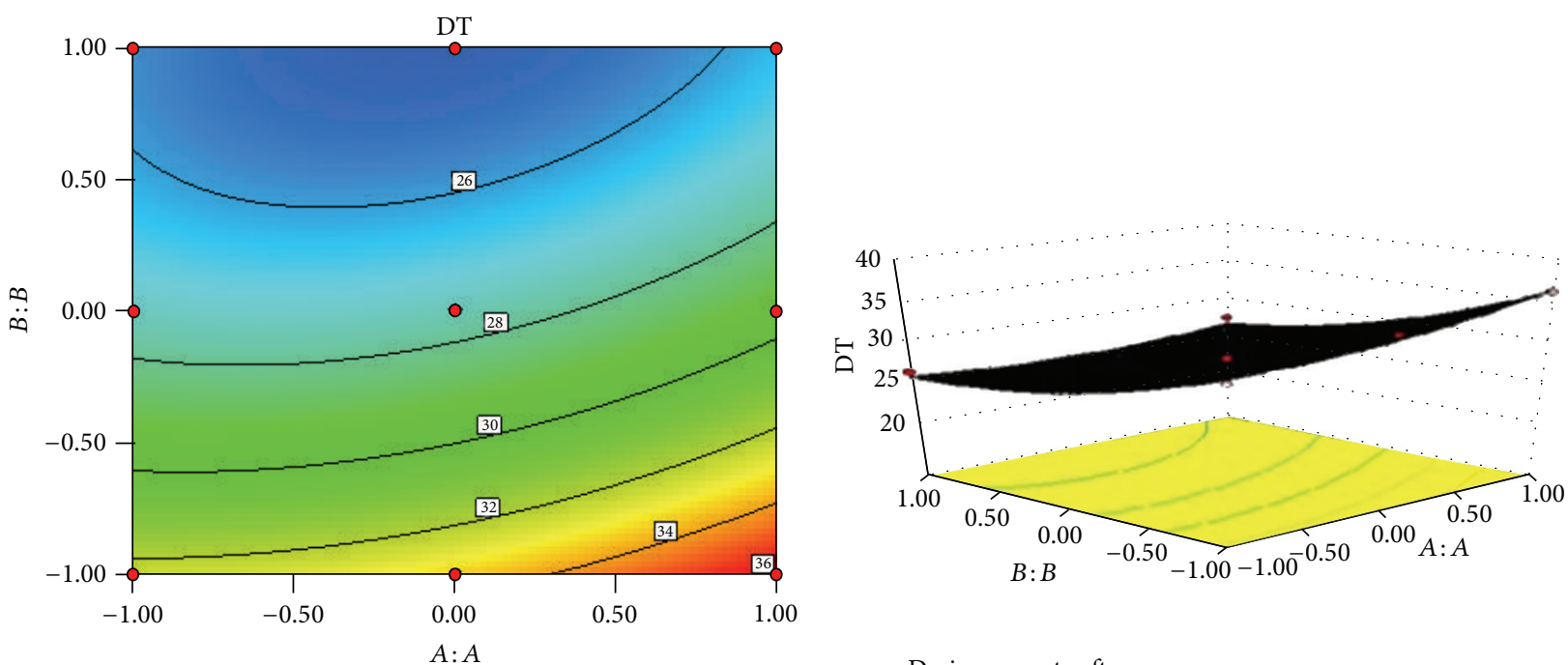

Design-expert software Factor coding: actual

R1

- Design points

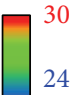

24

$X_{1}=A: A$

$X_{2}=B: B$

(a)

$$
\begin{aligned}
& \text { Design-expert software } \\
& \text { Factor coding: actual } \\
& \mathrm{R} 1 \\
& \text { ○ Design points above predicted value } \\
& \text { ○ Design points below predicted value } \\
& 30 \\
& X_{1}=A: A \\
& X_{2}=B: B
\end{aligned}
$$

(a)

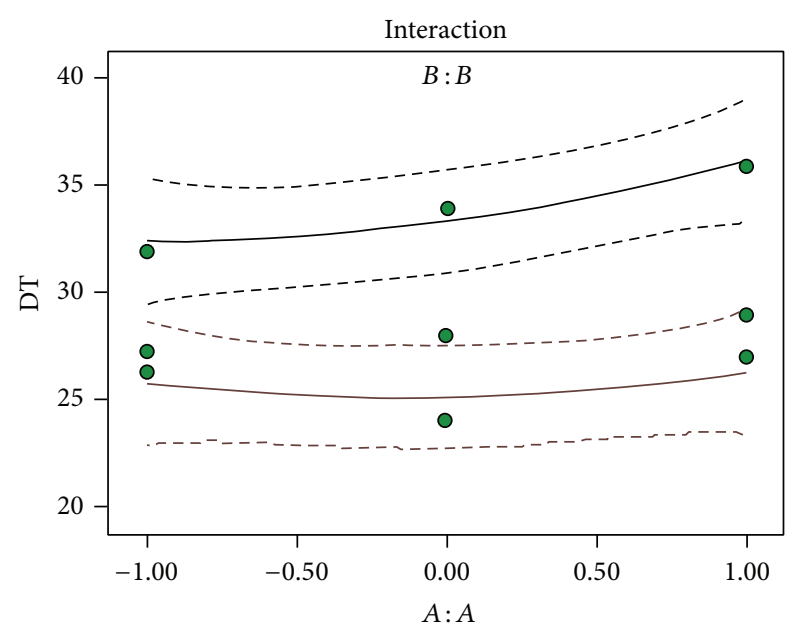

Design-expert software

Factor coding: actual

R1

$$
\begin{aligned}
& - \text { Cl bonds } \\
& \circ \quad \text { Design points } \\
& X_{1}=A: A \\
& X_{2}=B: B \\
& \text { - } B--1.00
\end{aligned}
$$$$
\Delta B+1.00
$$

(c)

Figure 5: (a) Contour plot showing the relationship between various levels of 2 independent variables. (b) Response surface plot showing the influence of film forming polymer (PVA) and superdisintegrant (SSG) over disintegration time. (c) Corresponding plot showing the interaction between two factors. 


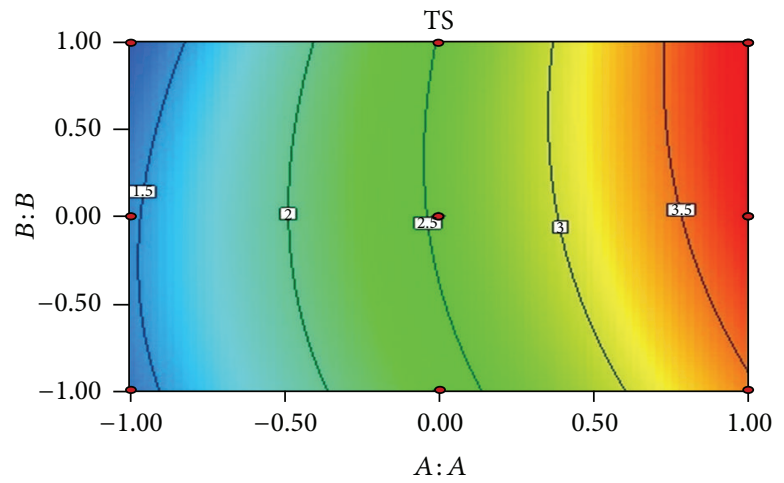

Design-expert software Factor coding: actual

R2

- Design points

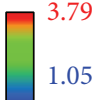

$X_{1}=A: A$

$X_{2}=B: B$

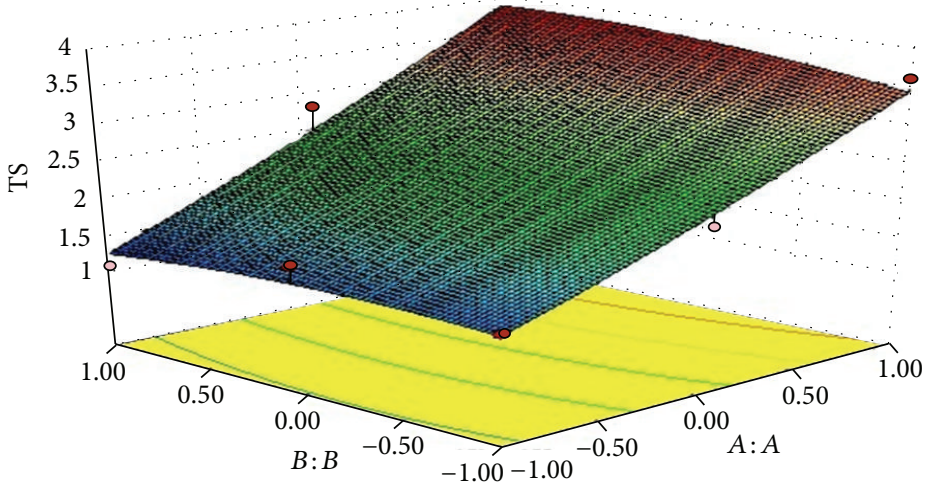

Design-expert software Factor coding: actual TS

- Design points above predicted value

- Design points below predicted value

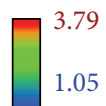

$X_{1}=A: A$

$X_{2}=B: B$

(a)

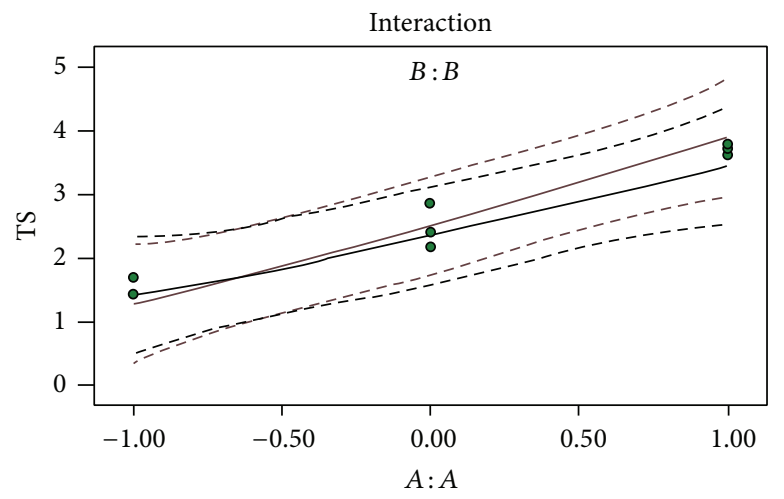

Design-expert software

Factor coding: actual

R2

$$
\begin{aligned}
& -\mathrm{Cl} \text { bonds } \\
& \circ \quad \text { Design points } \\
& X_{1}=A: A \\
& X_{2}=B: B \\
& \text { - } B--1.00 \\
& \Delta \quad B+1.00
\end{aligned}
$$

(c)

FIGURE 6: (a) Contour plot showing the relationship between various levels of 2 independent variables. (b) Response surface plot showing the influence of film forming polymer (PVA) and superdisintegrant (SSG) over tensile strength. (c) Corresponding plot showing the interaction between two factors. 


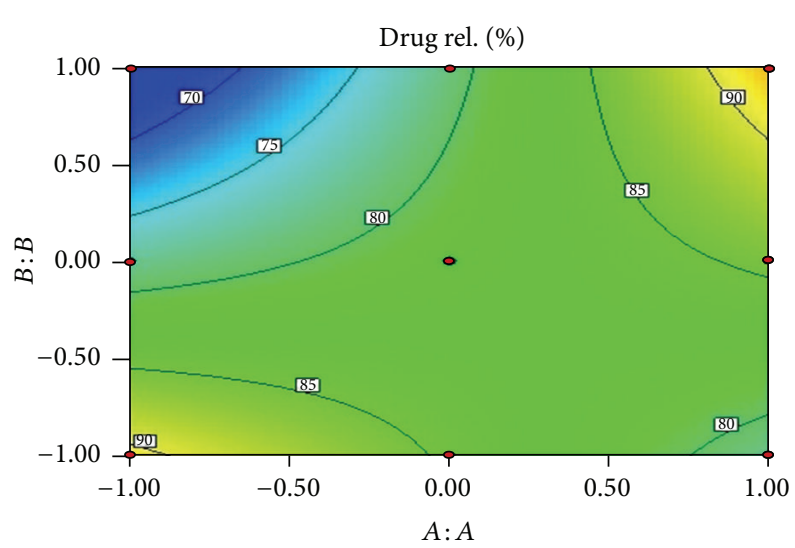

Design-expert software

Factor coding: actual

Drug rel. (\%)

- Design points

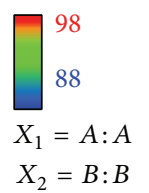

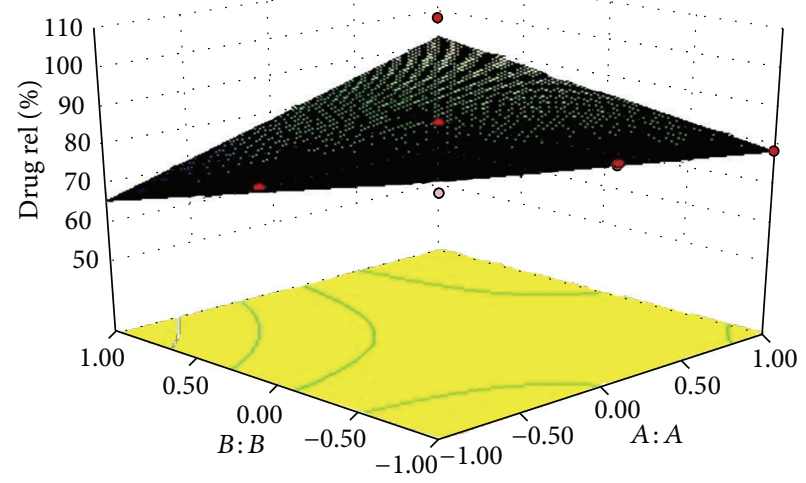

Design-expert software Factor coding: actual Drug rel. (\%)

- Design points above predicted value

- Design points below predicted value

$$
\begin{aligned}
& \square^{98} 88 \\
& X_{1}=A: A
\end{aligned}
$$$$
X_{2}=B: B
$$

(a)

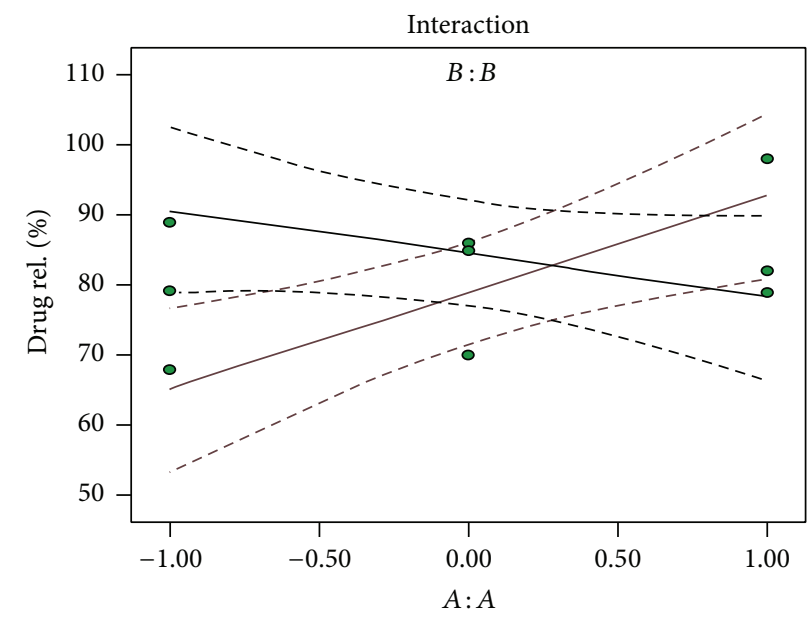

Design-expert software

Factor coding: actual

Drug rel. (\%)

$$
\begin{aligned}
& - \text { Cl bonds } \\
& \text { ○ Design points } \\
& X_{1}=A: A \\
& X_{2}=B: B \\
& \text { - } B--1.00 \\
& \triangle B+1.00
\end{aligned}
$$

(c)

Figure 7: (a) Contour plot showing the relationship between various levels of 2 independent variables. (b) Response surface plot showing the influence of film forming polymer (PVA) and superdisintegrant (SSG) over \% drug release. (c) Corresponding plot showing the interaction between two factors. 
TABLE 8: Comparison of the optimized formulation with marketed formulation $(n=3)$.

\begin{tabular}{lccc}
\hline Formulation & Disintegration time $(\mathrm{sec})$ & \% drug release & Thickness $(\mathrm{mm})$ \\
\hline Frisium & $65 \pm 1.53$ & $79.2 \pm 0.01$ & $3.80 \pm 0.02$ \\
F6 & $24 \pm 0.5$ & $96.6 \pm 0.05$ & $0.29 \pm 0.05$ \\
\hline
\end{tabular}

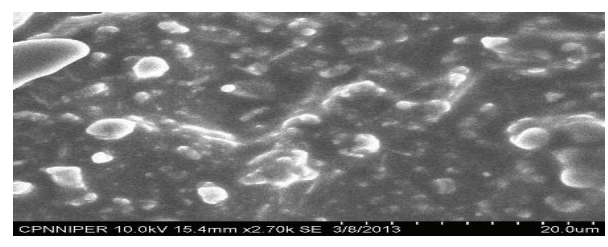

FIGURE 8: Surface morphology of optimized fast dissolving film formulation of F6.

3.4. In Vitro Disintegration Time of the Orally Dissolving Strips of Clobazam. In vitro disintegration time of the formulated orally dissolving strips was found to decrease with the addition of SSG. Increase in the concentration of superdisintegrant decreases the disintegration time of films, which was observed in F1, F2, F3, and F4; as the amount of PVA increases, the disintegration time increases because of the increasing thickness of the strip but again decreases with increasing amount of SSG and formulation with F6 exhibited minimum disintegration time. Mathematical relationship generated using multiple linear regression analysis for the studied variable is expressed as follows:

$$
\begin{aligned}
\text { disintegration time }= & 28.32222+1.56667 X_{1} \\
& -4.33333 X_{2}-0.075000 X_{1} X_{2} \\
& -0.33333 X_{1}^{2}+1.66667 X_{2}^{2} .
\end{aligned}
$$

The Model F-value of 42.62 implies that the model is significant.

3.5. In Vitro Dissolution Time. In vitro drug release was found to decrease with increase in the film forming polymer concentration which may be due to increase in the thickness of the oral strip and due to increase in the time required for wetting and dissolving the drug molecule present in the polymeric matrix but increase with increase in the concentration of the disintegrant. Formulations F1, F2, and F3 showed drug release up to $79.1 \%, 85 \%$, and $89 \%$, respectively, as shown in Figures 4(a), 4(b), and 4(c) at the end of $30 \mathrm{~min}$. Film formed with higher quantity of polymer had shown slower dissolution rate; this might be due to the increase level of PVA that results in formation of high viscosity gel layer due to more intimate contact between the particles of polymer resulting in decrease in the mobility of drug particles from the swollen matrix, which leads to a decrease in the release rate [32]. The order of drug release in each set of formulation can be given as

$$
\begin{aligned}
& \mathrm{F} 1<\mathrm{F} 2<\mathrm{F} 3, \\
& \mathrm{~F} 4<\mathrm{F} 5<\mathrm{F} 6, \\
& \mathrm{~F} 7<\mathrm{F} 8<\mathrm{F} 9 .
\end{aligned}
$$

The formulation F6 showed a maximum percentage drug release of $96.6 \%$ in $30 \mathrm{~min}$ as shown in Figure 4(b). Reflection point at $30 \mathrm{~min}$ in the curve might be due to the complete solubilization of PVA in the medium which improve the wettability and solubilize the drug and provide the fast dissolution rate. Further, drop in the percent of drug release after 30 min might be due to the availability of less number of drug molecules in the free void spaces and a decrease in mobility through polymeric matrix. Mathematical relationship generated using multiple linear regression analysis for the response variable is expressed as follows:

$$
\begin{aligned}
\% \text { drug release }= & 81.70111-5.16833 X_{1} \\
& +5.1683 X_{2}+1.00250 X_{1} X_{2} \\
& -4.5016 X_{1}^{2}+1.99833 X_{2}^{2} .
\end{aligned}
$$

The Model F-value of 77.23 implies that the model is significant.

3.6. Tensile Strength of the Orally Dissolving Strips of Clobazam. Tensile strength and \% elongation were found to increase with the increasing content of PVA which may be due the increase in the elasticity nature of the film forming polymer [33]. Mathematical relationship generated using multiple linear regression analysis for the studied variable is expressed as follows:

$$
\begin{aligned}
\text { Tensile strength }= & 2.39111+0.56500 X_{1} \\
& +0.31167 X_{2}-0.01500 X_{1} X_{2} \\
& -0.1916 X_{1}^{2}+0.12833 X_{2}^{2} .
\end{aligned}
$$

The Model F-value of 185.86 implies that the model is significant.

Addition of SSG affects tensile strength and \% elongation; higher concentration of SSG increases thickness and crystallinity of the film, which causes decrease in the tensile strength and \% elongation. The stress strain curve of optimized ODF formulation F6 is shown in Figure 3.

3.7. Release Kinetics. There was a good linear correlation $\left(R^{2}=0.9896-0.9999\right)$ obtained by plotting the percent 
TABLE 9: Intraday and interday precision accuracy of clobazam determination in rabbit plasma $(n=3)$.

\begin{tabular}{|c|c|c|c|c|c|c|}
\hline \multirow{2}{*}{$\begin{array}{l}\text { Clobazam } \\
\text { Concentration }(\mathrm{ng} / \mathrm{mL})\end{array}$} & \multicolumn{2}{|c|}{ Intraday } & \multicolumn{2}{|c|}{ Interday } & \multicolumn{2}{|c|}{ Accuracy } \\
\hline & Area & $\%$ RSD & Area & $\%$ RSD & $\begin{array}{c}\text { Quantity } \\
\text { Spiked (ng/mL) }\end{array}$ & Recovery \\
\hline 10 & 4.324 & 0.5 & 5.085 & 1.1 & 10 & 10.57 \\
\hline 20 & 6.049 & 0.9 & 6.158 & 1.1 & 20 & 18.09 \\
\hline 25 & 7.655 & 6.2 & 8.798 & 0.3 & 25 & 25.55 \\
\hline 40 & 12.06 & 3.0 & 12.24 & 0.8 & 40 & 39.36 \\
\hline 50 & 15.23 & 2.4 & 16.32 & 1.4 & 50 & 49.58 \\
\hline 75 & 22.88 & 0.8 & 20.59 & 0.4 & 75 & 74.76 \\
\hline 100 & 30.98 & 0.7 & 30.95 & 1.6 & 100 & 100.69 \\
\hline
\end{tabular}

TABLE 10: Comparison of pharmacokinetic parameters following administration of $5 \mathrm{mg}$ clobazam in orodispersible film (F6) and frisium tablets to six rabbits $(n=3)$.

\begin{tabular}{lccc}
\hline Parameters & Orodispersible film $($ mean $\pm \mathrm{SD})$ (test) & Frisium $($ mean $\pm \mathrm{SD})$ (reference) & Test/reference ratio \\
\hline$C_{\max }(\mathrm{ng} / \mathrm{mL})$ & $14.86 \pm 4.9$ & $15.545 \pm 5.1$ & 95.87 \\
$\left.\mathrm{AUC}_{0-t}(\mathrm{ng} \mathrm{hmL})^{-1}\right)$ & $87.018 \pm 19.2$ & $88.68 \pm 16.2$ & 98.125 \\
$\mathrm{AUC}_{0-\infty}\left(\mathrm{ng} \mathrm{hmL}^{-1}\right)$ & $90.726 \pm 15.3$ & $91.445 \pm 14.2$ & 99.213 \\
$t_{\max }(\mathrm{h})$ & $1.0 \pm 0.5$ & $1.4 \pm 0.5$ & 71.428 \\
$t_{1 / 2}(\mathrm{~h})$ & $42.52 \pm 12.5$ & $45.24 \pm 10.8$ & 93.987 \\
\hline
\end{tabular}

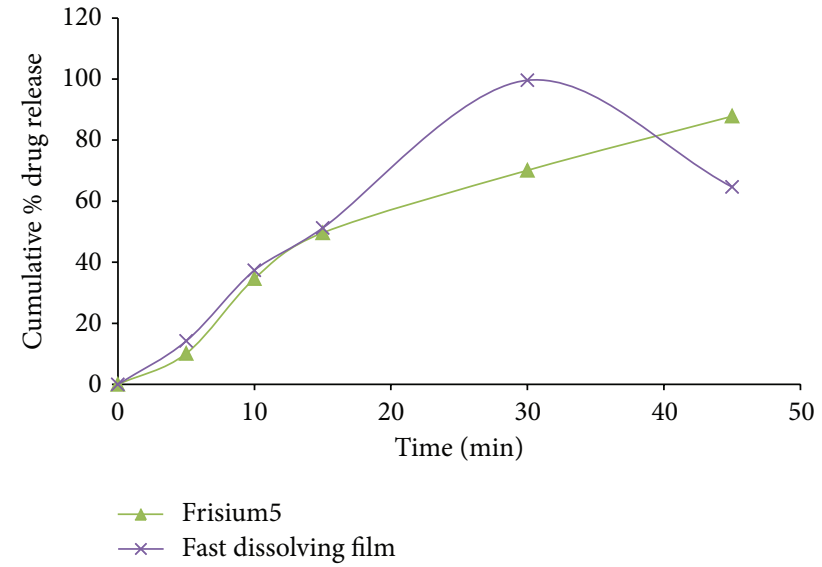

FIGURE 9: In vitro release profiles of clobazam from optimized ODF formulation F6 and frisium5. Mean $\pm n=3$.

of clobazam released from all the orally dissolving strip formulations against the square root of time. Thus, it was concluded that the release of clobazam from orally dissolving strip formulations followed a diffusion-controlled drug release profile and is in agreement with the Higuchi model. Results of release kinetics are shown in Table 5.

3.8. Regresion Analysis and Optimization. The results of multiple linear regression analysis are shown in Table 6, indicating that for all response variables which are disintegration time, tensile strength, and \% drug release, the amount of PVA $\left(X_{1}\right)$ had a negative effect while the concentration of SSG $\left(X_{2}\right)$ had a positive effect; it means that as the amount

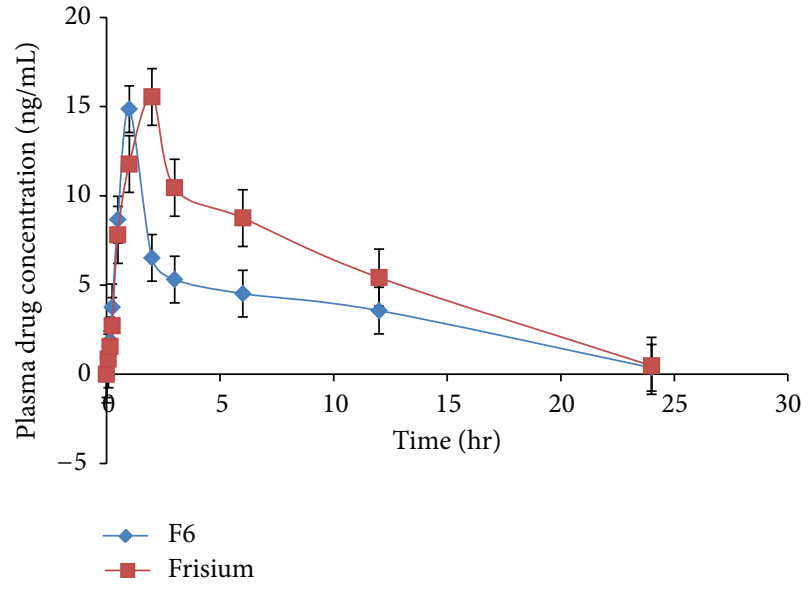

FIGURE 10: Means of plasma concentrations and time profiles of clobazam from (F6) ODF and marketed formulation (frisium5) mean $\pm \operatorname{SD} n=3$.

of SSG increases the tensile strength, disintegration time decreases and there is increase in \% drug release, while as the amount of PVA is increased, both the tensile strength and disintegration time increase [34-36]. Therefore, high level of SSG and medium level of PVA should be selected for the rapid disintegration and a faster in vitro drug release of the film. The observed values are in good agreement with the predicted values for the optimized formulation, which demonstrate the feasibility of surface response method in the formulation of oral fast dissolving films. The comparison of observed values and predicted values with \% prediction error is shown in Table 7 . The data of the response surface plot as shown in 
TABLE 11: Stability studies of optimized (F6) orally dissolving strip formulation of clobazam stored at $40^{\circ} \mathrm{C} / 75 \% \mathrm{RH}$.

\begin{tabular}{|c|c|c|c|c|c|c|}
\hline \multirow{2}{*}{ Parameters } & \multicolumn{6}{|c|}{ Time points (days) } \\
\hline & 0 & 15 & 30 & 45 & 60 & 90 \\
\hline Disintegration time (sec) & $24 \pm 0.5$ & $22.5 \pm 0.1$ & $23 \pm 0.2$ & $22 \pm 0.5$ & $23 \pm 0.4$ & $23.2 \pm 0.5$ \\
\hline Tensile strength $\left(\mathrm{N} / \mathrm{cm}^{2}\right)$ & $2.85 \pm 0.03$ & $2.80 \pm 0.02$ & $2.81 \pm 0.03$ & $2.85 \pm 0.03$ & $2.70 \pm 0.05$ & $2.80 \pm 0.05$ \\
\hline In vitro drug release (\%) & $96.6 \pm 0.74$ & $96.0 \pm 0.12$ & $96.0 \pm 0.02$ & $96.7 \pm 0.02$ & $96.8 \pm 0.61$ & $95.6 \pm 0.70$ \\
\hline
\end{tabular}

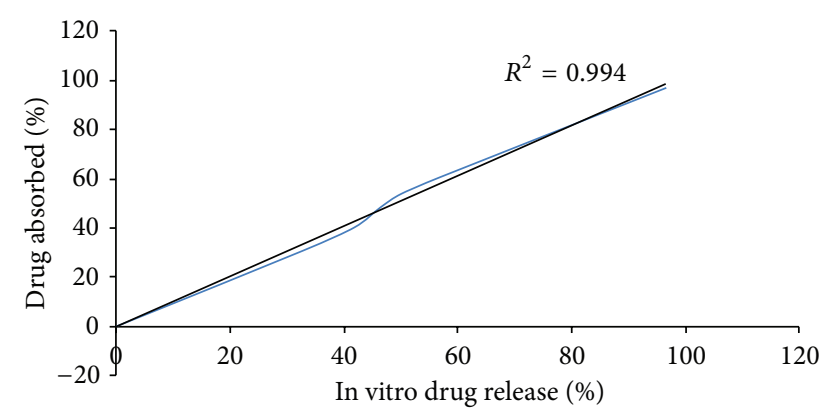

FIGURE 11: IVIVC plot for clobazam film formulation F6 in phosphate buffer $\mathrm{pH} 6.8$.

Figures 5, 6, and 7 demonstrated that both $X_{1}$ and $X_{2}$ affect the disintegration time, tensile strength, and $\%$ release of drug.

3.9. Scanning Electron Microscopy (SEM). The surface morphology as shown in Figure 8 using scanning electron microscopy of the optimized orally dissolving strip formulation of clobazam depicted smooth surface with some little pores, which is an indication of uniform distribution of drug particles.

3.10. Comparison of the Optimized Formulation with Marketed Formulation. Based on the responses the formulation F6 showing the highest dissolution rate, in vitro disintegration time suitable for fast-dissolving dosage form, and satisfactory tensile strength properties was chosen for subsequent comparative study relative to a marketed clobazam formulation as shown in Table 8. Comparative results of in vitro drug release of F6 formulation and marketed formulation (frisium5) as shown in Figure 9 indicate that the optimized formulation was comparable to the marketed formulation.

3.11. HPLC Method Validation Used to Quantify Clobazam in Rabbit Plasma. The results from the HPLC method validation in the rabbit plasma are shown in Table 9. The within day and between day precision as given in terms of $\%$ relative standard deviation ranged from 0.5 to $6.2 \%$ and from 1.1 to $1.6 \%$, respectively.

3.12. Pharmacokinetic Parameters. The mean clobazam plasma concentration time profiles for the prepared orally dissolving strip and the marketed tablets are shown in Figure 10. The statistical comparison of $C_{\max }, \mathrm{AUC}_{0-t}$, and

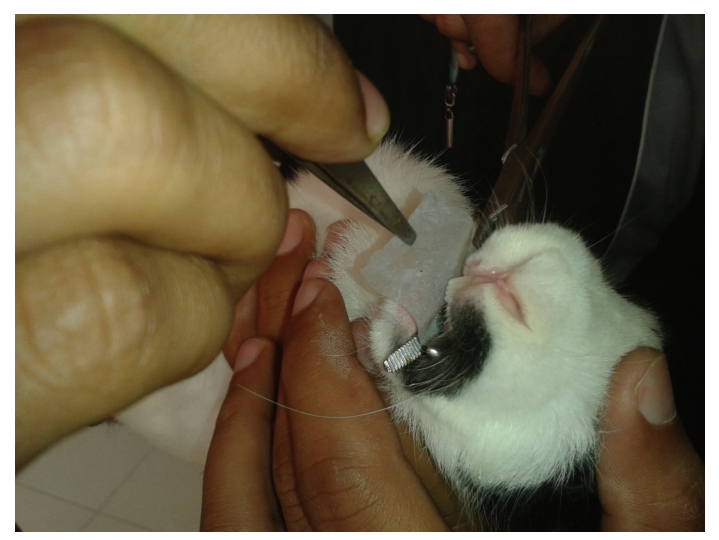

FIGURE 12: Bioavailability study on clobazam optimized ODF F6 and marketed formulation (frisium5).

$\mathrm{AUC}_{0-\infty}$ indicated no significant difference between the two treatments (test and reference marketed tablets). The $90 \%$ confidence intervals for the mean ratio (test/reference) of $C_{\max }, \mathrm{AUC}_{0-t}$, and $\mathrm{AUC}_{0-\infty}$ were $95.87 \%, 98.12 \%$, and $99.21 \%$, respectively, and are shown in Table 10, while the acceptable range is $80-125 \%$ for $\mathrm{AUC}_{0-t}$ and $\mathrm{AUC}_{0-\infty}$, and $70-143 \%$ for $C_{\max }$, as proposed by the FDA [37].

3.13. IVIV Correlation. In vitro-in vivo correlation as shown in Figure 11 of percentage drug absorbed and percentage drug released showed good in vitro-in vivo correlation for optimized film formulation F6 with $R^{2}$ value 0.994 .

3.14. Stability Studies. The optimized formulation F6 was selected for the stability study. Stability data are shown in Table 11. It was concluded that there was no significant change observed in the weight of orally dissolving strip, tensile strength, and $\%$ in vitro drug release. The average clobazam content of formulation F6 after 6-month storage was 95.1 $\pm 0.17 \mathrm{mg}$ (ranging from 91.88 to $96.80 \%$ ). The appearance of the film after storage for 6 months remained unchanged. Therefore, the prepared formulation was stable up to 6 months at $40^{\circ} \mathrm{C}(75 \% \mathrm{RH})$.

\section{Conclusion}

The orally dissolving strips of clobazam prepared using PVA as film forming material and SSG as disintegrant by the solvent-casting method showed satisfactory drug dissolution and acceptable physicomechanical characteristics. $3^{2}$ factorial 
design was used for the optimization, amongst nine formulations prepared as per the design layout, which indicates that the film prepared using $100 \mathrm{mg}$ of PVA and 6\% of SSG (F6) showed the highest dissolution rate, suitable in vitro disintegration time, and satisfactory tensile strength and was selected as the optimized formulation. In vivo studies also indicated absence of significant difference between F6 and frisium 5 marketed tablets and both exhibited comparable drug plasma level-time profiles. Accelerated stability studies results showed that prepared formulation was stable enough for the period of at least 6 months. Therefore, the present orodispersible film formulation containing clobazam considered is potentially useful for the treatment of epileptic attack where improved patient compliance and convenience are expected and can be used as an alternative to the fast dissolving tablet formulation.

\section{Conflict of Interests}

The authors report no conflict of interests.

\section{Acknowledgments}

The authors are thankful to the management of Chitkara College of Pharmacy, Chitkara University, Chandigarh, India, for providing all facilities to carry out research work, Consern Pharma, Ludhiana, Punjab, India, for providing the gift sample of clobazam, Central Instrumentation Lab NIPER Mohali, Punjab, India, for providing the facility of FTIR, DSC, and SEM analysis, and Central Institute of Post Harvesting Engineering and Technology (CIPHET), Ludhiana, for providing the facility of tensile strength determination.

\section{References}

[1] A. Arya, A. Chandra, V. Sharma, and K. Pathak, "Fast dissolving oral films: an innovative drug delivery system and dosage form," International Journal of ChemTech Research, vol. 2, no. 1, pp. 576-583, 2010.

[2] K. Sharma, W. R. Pfizer, and T. K. Ghosh, "Quick-dispersing oral drug delivery systems," in Drug Delivery to the Oral Cavity Molecule to Market, vol. 145, pp. 262-287, 2005.

[3] F. Cilurzo, I. E. Cupone, P. Minghetti, F. Selmin, and L. Montanari, "Fast dissolving films made of maltodextrins," European Journal of Pharmaceutics and Biopharmaceutics, vol. 70, no. 3, pp. 895-900, 2008.

[4] S. K. Yellanki, S. Jagtap, and R. Masareddy, "Dissofilm: a novel approach for delivery of phenobarbital; design and characterization," Journal of Young Pharmacists, vol. 3, no. 3, pp. 181-188, 2011.

[5] T. Hanawa, "Development of a new and kindly oral dosage form for elderly," Journal of Pharmaceutical Science and Technology, vol. 13, no. 4, pp. 251-258, 1997.

[6] H. Goel, P. Rai, V. Rana, and A. K. Tiwary, "Orally disintegrating systems: innovations in formulation and technology," Recent Patents on Drug Delivery and Formulation, vol. 2, no. 3, pp. 258274, 2008.

[7] R. Mishra and A. Amin, "Formulation development of tastemasked rapidly dissolving films of cetirizine hydrochloride," Pharmaceutical Technology, vol. 33, no. 2, pp. 48-56, 2009.
[8] H. Shimoda, K. Taniguchi, M. Nishimura et al., "Preparation of a fast dissolving oral thin film containing dexamethasone: a possible application to antiemesis during cancer chemotherapy," European Journal of Pharmaceutics and Biopharmaceutics, vol. 73, no. 3, pp. 361-365, 2009.

[9] S. B. Borsadia, D. O'Halloran, and J. L. Osborne, "Quickdissolving films - a novel approaches to drug delivery," Drug Development and Delivery, vol. 3, no. 3, pp. 63-66, 2003.

[10] K. K. Peh and C. F. Wong, "Polymeric films as vehicle for buccal delivery: swelling, mechanical, and bioadhesive properties," Journal of Pharmacy and Pharmceutical Sciences, vol. 2, no. 2, pp. 53-61, 1999.

[11] C. M. Corniello, "Quick dissolve strips: from concept to commercialization," Drug Delivery Technology, vol. 6, pp. 68-71, 2006.

[12] S. Ali and A. Quadir, "High molecular weight povidone polymer-based films for fast-dissolving drug delivery Application," Drug Delivery Technology, vol. 7, pp. 36-43, 2007.

[13] K. S. Kulkarni, H. A. Deokule, M. S. Mane, and D. M. Ghadge, "Exploration of different polymers for use in the formulation of oral fast dissolving strips," Journal of Current Pharmacy Research, vol. 2, pp. 33-35, 2010.

[14] S. Malke, S. Shidhaye, J. Desai, and V. Kadam, "Oral filmspatient compliant dosage form for pediatrics," Internet Journal of Pediatrics and Neonatology, vol. 11, no. 2, 2010.

[15] B. Martineau, "A look at fast-dissolving drug delivery systems," Drug Delivery Technology, vol. 9, no. 4, pp. 36-38, 2009.

[16] D. L. Keene, S. Whiting, and P. Humphreys, "Clobazam as an add-on drug in the treatment of refractory epilepsy of childhood," Canadian Journal of Neurological Sciences, vol. 17, no. 3, pp. 317-319, 1990.

[17] M. J. Mohammed and O. S. Ali, "Clobazam for the treatment of intractable childhood epilepsy," Saudi Medical Journal, vol. 21, p. $62,2000$.

[18] T. Higuchi and K. A. Conner, "Phase-solubility techniques," Advances in Analytical Chemistry and Instrumentation, vol. 4, pp. 117-122, 1965.

[19] R. Mishra and A. Amin, "Manufacturing techniques of orally dissolving films," Pharmaceutical Technology, vol. 35, no. 1, pp. 70-73, 2011.

[20] M. Dhanasree, "Analytical method development and validation of clobazam by using UV spectrophotometric method," The Experiment, vol. 1, no. 1, pp. 22-28, 2012.

[21] J. H. Park, K. M. Holman, G. A. Bish et al., "An alternative to the USP disintegration test for orally disintegrating tablets," Pharmaceutical Technology, vol. 32, no. 8, pp. 54-58, 2008.

[22] S.-Y. Lin, "Effect of excipients on tablet properties and dissolution behavior of theophylline-tableted microcapsules under different compression forces," Journal of Pharmaceutical Sciences, vol. 77, no. 3, pp. 229-232, 1988.

[23] J. G. Wagner, "Interpretation of percent dissolved-time plots derived from in vitro testing of conventional tablets and capsules.", Journal of Pharmaceutical Sciences, vol. 58, no. 10, pp. 1253-1257, 1969.

[24] T. Higuchi, "Mechanism of sustained-action medication: theoretical analysis of rate of release of solid drugs dispersed in solid matrices," Journal of pharmaceutical sciences, vol. 52, pp. 11451149, 1963.

[25] R. P. Dixit and S. P. Puthli, "Oral strip technology: overview and future potential," Journal of Controlled Release, vol. 139, no. 2, pp. 94-107, 2009. 
[26] I. S. Chronakis, "On the molecular characteristics, compositional properties, and structural-functional mechanisms of maltodextrins: a review," Critical Reviews in Food Science and Nutrition, vol. 38, no. 7, pp. 599-637, 1998.

[27] R. Khanna, S. P. Agarwal, and A. Ahuja, "Preparation and evaluation of muco-adhesive buccal films of clotrimazole for oral Candida infections," Indian Journal of Pharmaceutical Sciences, vol. 59, no. 6, pp. 299-305, 1997.

[28] M. E. Aulton, M. H. Abdul-Razzak, and J. E. Hogan, "The mechanical properties of hydroxypropylmethylcellulose films derived from aqueous systems. Part 1: the influence of plasticisers," Drug Development and Industrial Pharmacy, vol. 7, no. 6, pp. 649-668, 1981.

[29] P. Venkatesh, R. Rajesh Kumar, A. Rajasekaran, and D. J. Dharman, "Bioanalytical method development and comparative bioavailability study of clobazam tablets in albino rats plasma using RP-HPLC method," Digest Journal of Nanomaterials and Biostructures, vol. 5, no. 2, pp. 403-409, 2010.

[30] M. Rezarouini, Y. Ardakani, M. Shohrati, and L. Hakemi, "Pharmacokinetic and bioequivalence study of clobazam $10 \mathrm{mg}$ tablet," International Journal of pharmacology, vol. 2, pp. 409481, 2001.

[31] D. A. El-Setouhy and N. S. A. El-Malak, "Formulation of a novel tianeptine sodium orodispersible film," AAPS PharmSciTech, vol. 11, no. 3, pp. 1018-1025, 2010.

[32] N. B. Modi, M. Dakshina, S. Gangadhar, and Y. David, "In vitroin vivo correlation," in Pharmaceutical Product Development, pp. 107-123, Informa healthcare, London, UK, 1st edition, 2007.

[33] P. K. Kulkarni, M. Dixit, K. Gunashekara, A. Shahnawaz, M. N. Singh, and A. Kulkarni, "Formulation and evaluation of mouth dissolving film containing Rofecoxib," International Research Journal of Pharmacy, vol. 2, pp. 177-178, 2010.

[34] V. Y. Londhe and K. B. Umalkar, "Formulation development and evaluation of fast dissolving film of telmisartan," Indian Journal of Pharmaceutical Sciences, vol. 74, no. 2, pp. 122-126, 2012.

[35] P. Prabhu, R. Malli, M. Koland et al., "Formulation and evaluation of fast dissolving films of levocitirizine dihydrochloride," International Journal of Pharmaceutical Investigation, vol. 1, no. 2, pp. 99-104, 2011.

[36] R. Ilango, S. Kavimani, A. R. Mullaicharam, and B. Jayakar, "In vitro studies on buccal strips of glibenclamide using chitosan," Indian Journal of Pharmaceutical Sciences, vol. 59, no. 5, pp. 232235, 1997.

[37] B. K. Satishbabu and B. P. Srinivasan, "Preparation and evaluation of buccoadhesive films of atenolol," Indian Journal of Pharmaceutical Sciences, vol. 70, no. 2, pp. 175-179, 2008. 

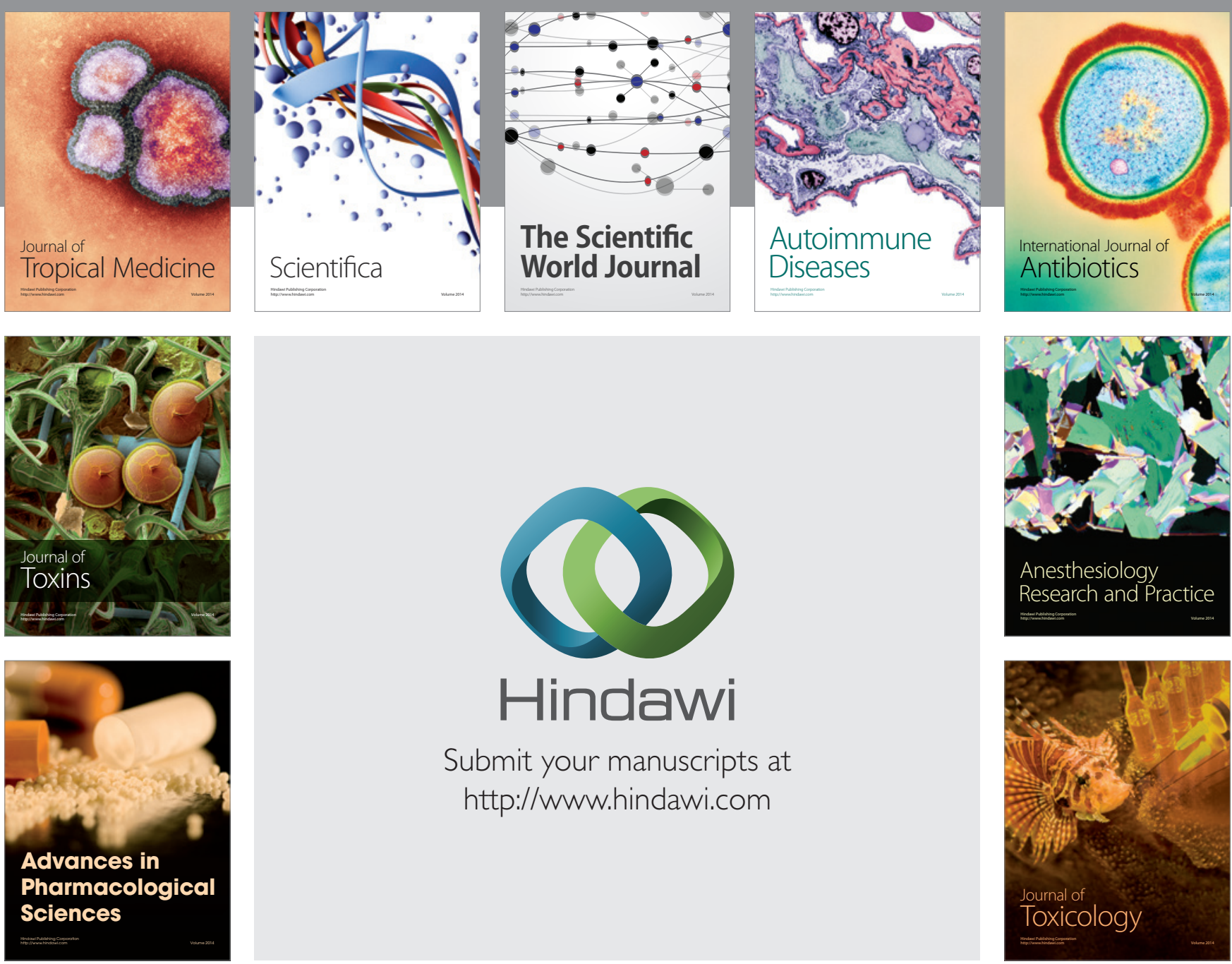

\section{Hindawi}

Submit your manuscripts at

http://www.hindawi.com
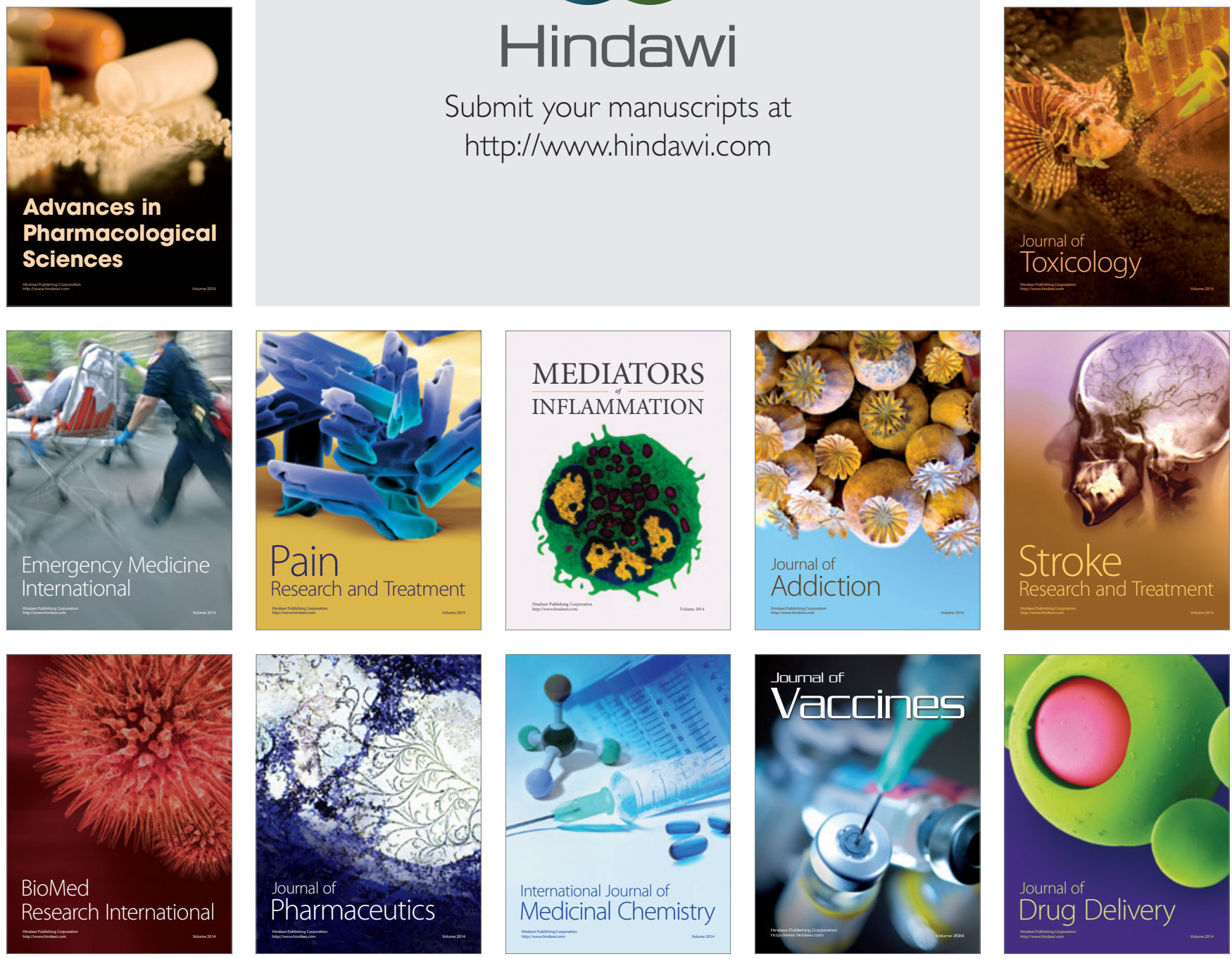